$$
\text { 주거지역 환경소음에 대한 거주민 의식 분석 }
$$

\title{
Analysis of Residents' Consciousness for the Environmental Noise in the Residential Area
}

\author{
박 현 구†.송 국 곤*. 김 원 식*. 김 선 우** \\ Hyeon Ku Park, Guk Gon Song, Won Sik Kim and Sun-Woo Kim \\ (2011년 9월 29일 접수 ; 2011년 12월 30일 심사완료)
}

Key Words : Environmental Noise(환경소음), Consciousness(의식), Comfortable Residential Environment(쾌적 한 주거환경)

\begin{abstract}
Environmental noise in the residential area is appeared with different types and features along with the growth of society. In particular when the economic level is raised up, the demand of residents for the environmental noise becomes more sensitive. The existing research on the environmental noise was initiated in the 1980's and resulted that the children's jumping sound was most annoying among the noises transmitted from the other unit. This result caused such activities that the researches were focused on the floor impact noise and that the laws in relation to environmental noise within residential area were revised strictly. This study aimed to survey the consciousness of residents for the environmental noise and to see how it is changed comparing with the previous one. Ultimately this result could be useful to establish the target for research or noise control to make the comfortable residential environment.
\end{abstract}

\section{1. 서 론}

\section{1 연구의 필요성 및 목적}

1980년대 주택경기활성화로 시작된 공동주택의 공급은 현재까지 지속적으로 증가추세에 있다. 또 한 삶의 질적 향상과 더불어 환경에 대한 관심이 증가함에 따라 공동주택의 주거환경과 그 개선방 안에 대한 연구가 많이 진행되어 왔다. 특히 중요 한 주거환경 요소 중의 하나인 소음환경에 대한

† 교신저자; 정회원, 전남대학교 바이오하우징연구사업단 E-mail : soundpark@cricmail.net

Tel : (062)530-0639, Fax : (062)530-0780

* 전남대학교 대학원 건축공학과

** 정회원, 전남대학교 건축학부

\# 이 논문의 일부는 2011년 춘계 소음진동 학술대회에서 발표되었음.
분쟁 건수가 계속 증가하고 있으며(1) 이에 대한 연구가 지속적으로 진행되고 있다. 주거환경소음 은 사회의 변화에 따라 발생하는 양상, 특성이 달 라진다. 특히 경제수준이 향상될수록 주거공간에 서의 소음에 대한 거주민의 관심은 당연히 높아 질 수밖에 없다.

공동주택의 공급이 활성화되던 1980년대 중반 이후를 시점으로 주거소음환경 수준과 문제점의 평가 방법 중의 하나로 설문조사를 통해 실제 거 주자들의 주관적 반응을 조사하는 방법이 사용되 어 왔다. 이러한 조사는 대표적으로 1986년, 1996 년 연구가 진행되었으며, 이에 대한 지속적인 연 구로 현 시점에서의 주거소음환경에 대한 설문조 사를 진행할 필요성이 있다.

이 연구에서는 현 시점에서의 주거소음환경에 대한 설문조사를 실시하여, 선행 연구 결과와의 
비교 분석을 통해 거주자들의 주거소음환경에 대 한 주관적 반응의 변화 추이의 분석을 통해 소음 환경의 개선안을 찾는 기초 연구로 활용하고자 한다.

\section{2 선행 연구 고찰}

1986년 김선우 등의 연구(2)에서는 서울, 광주, 대 구, 대전의 대도시 주거단지에 거주하는 주부를 대 상으로 내부소음과 외부소음의 실태를 조사하였다. 조사결과 실내소음원 중 가장 문제시 되는 소음으 로 '아이들 뛰노는 소리'와 같은 충격음과 '욕조 급 배수음'과 같은 급배수 소음에 대한 지적률이 $40 \%$ 이상으로 높게 나타났다. 외부소음의 경우 ‘외부 차 량 소음'에 대한 지적률이 $46 \%$ 로 높게 나타나 실 제 거주자들이 느끼는 외부소음의 주된 소음원으로 지적 되었다.

1996년 박주욱 등의 연구(3)에서는 1990년대 이후 입주가 이루어진 공동주택 주거단지 거주자를 대상 으로 내부소음과 외부소음에 대한 실태를 파악하고 주거환경소음에 대한 의식변화를 고찰하였다. 내부 소음에서는 여전히 '아이들 뛰노는 소리'가 가장 신 경쓰이는 소리로 지적되었으며, 엘리베이터의 등장 으로 인해 엘리베이터 소음이 상위 5 개의 신경쓰이 는 소리 안에 포함되었다. 이전의 조사와는 대조적 으로 쓰레기 분리수거의 실시와 함께 더스트 슈트 (dust chute)의 사용이 중지됨으로써 '쓰레기 버리는 소리'에 대한 지적률이 크게 낮아졌다.

곽경숙 등의 연구 ${ }^{(4)}$ 에서는 전주시의 아파트 거주 자를 대상으로 아파트 소음환경에 대한 거주자의 주관적 평가를 실시하였다. 외부소음과 내부소음을 고체전달음과 공기전달음으로 나누어 분석하였다. 외부소음 중 낮 시간의 ‘판매 스피커 소리', 저녁 시간의 ‘놀이터 아이들 소리', ‘발자국 소리', 밤 시 간에는 '교통소음'을 크게 의식하고 있으며, 수면, 집중력, 휴식 등에 상당한 방해를 받고 있는 것으로 나타났다. 그러나 대화나 $\mathrm{TV}$, 음악 감상 등에는 그 다지 방해를 받지 않고 있었다. 내부소음은 고체전 달음에 대한 의식 중 급배수 소음은 저층에서 크게 느끼고 있었고, 공기전달음은 크게 의식하지 않고 있었다. 내부소음은 거의 저녁 시간에 심하게 느끼 고 있었으며, 소음을 가장 심하게 느끼는 계절은 여 름으로 나타났다.

\section{2. 연구방법}

\section{1 조사 대상}

광주광역시의 유동 인구와 공동주택 거주자를 대 상으로 설문을 실시하였으며, 또한 웹 서버를 통해 주민들의 설문 참여를 통해 그 자료를 수합하였다. 수합된 전체 응답 중 중복 응답 등 부적절한 응답 지를 제외한 550 부를 분석에 사용하였다. 수집된 자료는 SPSS 19.0을 사용하여 통계처리 하였으며, 빈도, 백분율, 표준편차(SD), t-test, 일원변량분석을 실시하였다.

\section{2 조사 내용}

설문지는 선행연구를 기초로 항목을 결정한 후 작성하였으며, 이 연구에 사용된 설문은 거주지의 ‘외부소음환경', ‘실내소음환경', ‘일반사항'의 세 부 분으로 이루어졌다.

외부소음환경에 대한 조사에서는 '거주지 외부소 음에 대한 응답자의 만족도', '거주지 외부소음이 발생하는 정도', ‘외부소음에 대해 신경 쓰이는 정 도'에 대해서 조사하였다.

내부소음환경에 대한 조사에서는 '거주지 내부소 음이 발생하는 정도', '내부소음에 대해 신경쓰이는 정도'에 대해서 조사하였다.

마지막으로 일반사항에서는 응답자의 인구통계학 적 특성을 파악하기 위해 거주자의 '성별', '나이', '직업'을 조사하였고, 거주형태의 파악을 위해 '거주 형태', ‘현재 거주지의 거주 층수', ‘거주 기간', ‘입 주방식', ‘준공년도', ‘발코니 확장 여부, 등에 대해 서 조사하였다.

기존의 연구에서는 1996년 내부소음환경 평가 항목에 세탁기 가동음, 베란다 배수음, 난방 보일 러 소음, 엘리베이터 운행소음, 지하 기계실 소음, 옥상 물탱크 급수음의 6가지 항목이 1986년 연구 항목에 추가 되었고, 외부소음환경에 대해서는 1986년에만 항목별 조사가 이루어졌고 1996년에 는 외부소음 정도와 불만족도 등의 시간별 조사 가 이루어 졌다.

이 연구에서는 물건 떨어뜨리는 소리와 에어컨 실외기 소리를 내부소음항목에 포함시키고, 쓰레기 버리는 소리는 삭제하였다. 그리고 외부소음 항목에 
철도소음, 항공기소음, 공장기계소음, 건설공사장 소 음, 발파소음, 새나 동물들 짖는 소리 등의 6 가지 항목을 추가하였다.

Table 1은 선행 연구 및 이 연구에서 사용된 조 사항목을 정리, 비교한 것이다.

\section{3 평가 방법 및 평가 도구}

소음의 종류를 크게 외부소음과 내부소음으로 구 분하여 설문조사를 실시하였다. 설문을 통해 소음의 발생 빈도, 신경쓰이는 정도를 조사하였으며, 응답 자의 특성 및 주거 특성을 조사하였다.

평가척도는 선행연구 결과를 토대로 '매우'와 '전 혀'를 양극으로 하여 7단계 척도로 소음 발생 빈도, 만족도, 신경쓰이는 정도를 평가하였다.

\section{3. 결과 분석 및 고찰}

\section{1 사회인구통계학적 특성}

설문조사에 참여한 응답자들의 사회인구통계학 적 특성은 Table 2에 나타난 바와 같이 여성이 $58.7 \%$, 남성이 $41.3 \%$ 이고, 연령별로 20 대가 43.2 $\%, 30$ 대가 $25.2 \%$ 로 나타났다. 직업별로는 학생, 사무/행정, 의료/서비스, 교육에 종사하는 사람이 대다수를 차지했다.

응답자의 주거 형태는 아파트 및 연립 주택의 공 동주택이 $77.7 \%$ 로 가장 높게 나타났고, 단독주택 이 $16.0 \%$ 로 나타났다. 기타로 기숙사, 원룸, 주상 복합건물 등이 있었다.

Table 1 Items for the survey of consciousness on noise

\begin{tabular}{|c|c|c|c|}
\hline $\begin{array}{l}\text { Year } \\
\text { surveyed } \\
\text { Type of } \\
\text { sound }\end{array}$ & $1986^{(2)}$ & $1996^{(5)}$ & 2010 \\
\hline $\begin{array}{l}\text { Indoor } \\
\text { noise }\end{array}$ & $\begin{array}{l}\text { Entrance door opening or closing } \\
\text { Window opening or closing } \\
\text { Footsteps at stairway or corridor } \\
\text { Footsteps in room } \\
\text { Plumbing by bathtub } \\
\text { Exhausting by chamber pot } \\
\text { Plumbing in the kitchen } \\
\text { Cooking in the kitchen } \\
\text { TV or radio } \\
\text { Musical instruments like piano } \\
\text { Doorbell } \\
\text { Children playing } \\
\text { Speaking like phone call } \\
\text { Discarding garbage } \\
\text { Urinating in bathroom }\end{array}$ & $\begin{array}{l}\text { Entrance door opening or closing } \\
\text { Window opening or closing } \\
\text { Footsteps at stairway or corridor } \\
\text { Footsteps in room } \\
\text { Plumbing by bathtub } \\
\text { Exhausting by chamber pot } \\
\text { Plumbing in the kitchen } \\
\text { Cooking in the kitchen } \\
\text { TV or radio } \\
\text { Musical instruments like piano } \\
\text { Doorbell } \\
\text { Children playing } \\
\text { Speaking } \\
\text { Discarding garbage } \\
\text { Urinating in bathroom } \\
\text { Washing machine } \\
\text { Plumbing at balcony } \\
\text { Heating boiler } \\
\text { Elevator working } \\
\text { Engine room at basement } \\
\text { Supplying water in rooftop water } \\
\text { tank }\end{array}$ & $\begin{array}{l}\text { Entrance door opening or closing } \\
\text { Window opening or closing } \\
\text { Footsteps at stairway or corridor } \\
\text { Footsteps in room } \\
\text { Plumbing by bathtub } \\
\text { Exhausting by chamber pot } \\
\text { Plumbing in the kitchen } \\
\text { Cooking in the kitchen } \\
\text { TV or radio } \\
\text { Musical instruments like piano } \\
\text { Doorbell } \\
\text { Children jumping and running } \\
\text { Speaking } \\
\text { Urinating in bathroom } \\
\text { Washing machine } \\
\text { Plumbing at balcony } \\
\text { Heating boiler } \\
\text { Elevator working } \\
\text { Engine room at basement } \\
\text { Supplying water in rooftop water } \\
\text { tank } \\
\text { Dropping small stuff } \\
\text { Outdoor unit of air conditioner }\end{array}$ \\
\hline $\begin{array}{c}\text { Outdoor } \\
\text { noise }\end{array}$ & $\begin{array}{l}\text { Transportation sound } \\
\text { Children playing } \\
\text { Sale of street vendors } \\
\text { Neighborhood } \\
\text { Loud speaker }\end{array}$ & & $\begin{array}{l}\text { Road traffic noise } \\
\text { Children playing } \\
\text { Sale of street vendors } \\
\text { Neighboring store } \\
\text { Railway noise } \\
\text { Aircraft noise } \\
\text { Machinery sound from factory } \\
\text { Constructing sound } \\
\text { Blasting sound } \\
\text { Sound by animal like bird's } \\
\text { chirping, dog's barking }\end{array}$ \\
\hline
\end{tabular}


현재 건물에서의 거주기간을 묻는 질문에 3 년 이 하의 응답자가 $29.0 \%$ 로 가장 많았고, 11 년 이상의 응답자는 $14.2 \%$ 로 가장 적으며, 1 년 이하, 5 년 이 하, 10 년 이하의 경우 비슷한 수준을 나타냈다.

거주층은 1 층에서 5 층이 $48.3 \%$ 를 차지하였고, 6 층에서 10 층은 $22.9 \%, 11$ 층에서 15 층은 $17.7 \%$, 16 층 이상은 $9.9 \%$ 를 차지하였다.

Table 2 Description of respondents

\begin{tabular}{|c|c|c|c|}
\hline \multicolumn{2}{|c|}{ Item } & $\begin{array}{l}\text { Frequency } \\
(\mathrm{N})\end{array}$ & $\begin{array}{c}\text { Percentage } \\
(\%)\end{array}$ \\
\hline \multirow{2}{*}{ Gender } & Male & 229 & 41.26 \\
\hline & Female & 326 & 58.74 \\
\hline \multirow{5}{*}{ Age } & $10 \sim 19$ years & 52 & 9.37 \\
\hline & 20 29 years & 240 & 43.24 \\
\hline & 30 39 years & 140 & 25.23 \\
\hline & 40 49 years & 82 & 14.77 \\
\hline & 50 years $\sim$ & 41 & 7.39 \\
\hline \multirow{7}{*}{ Occupation } & $\begin{array}{c}\text { Industry/ } \\
\text { manufacture }\end{array}$ & 17 & 3.06 \\
\hline & $\begin{array}{c}\text { Medical } \\
\text { field/service }\end{array}$ & 54 & 9.73 \\
\hline & Office/business & 130 & 23.42 \\
\hline & Education & 125 & 22.52 \\
\hline & House wife & 35 & 6.31 \\
\hline & Student & 144 & 25.95 \\
\hline & Etc. & 50 & 9.01 \\
\hline \multirow{3}{*}{$\begin{array}{l}\text { Type of } \\
\text { house }\end{array}$} & Single house & 89 & 16.04 \\
\hline & $\begin{array}{c}\text { Apartment } \\
\text { or row house }\end{array}$ & 431 & 77.66 \\
\hline & Etc. & 35 & 6.31 \\
\hline \multirow{5}{*}{$\begin{array}{l}\text { Period of } \\
\text { residence }\end{array}$} & Below 1 year & 105 & 18.92 \\
\hline & 1 3 years & 161 & 29.01 \\
\hline & $4 \sim 5$ years & 87 & 15.68 \\
\hline & $6 \sim 10$ years & 114 & 20.54 \\
\hline & $\begin{array}{l}\text { More than } \\
10 \text { years }\end{array}$ & 79 & 14.23 \\
\hline \multirow{4}{*}{ Ownership } & $\begin{array}{c}\text { Private } \\
\text { residence }\end{array}$ & 338 & 60.90 \\
\hline & $\begin{array}{c}\text { Lease on a } \\
\text { deposit basis }\end{array}$ & 132 & 23.78 \\
\hline & Lease & 31 & 5.59 \\
\hline & Monthly rent & 51 & 9.19 \\
\hline \multirow{5}{*}{$\begin{array}{l}\text { Number of } \\
\text { floor }\end{array}$} & $1 \mathrm{st} \sim 5$ th & 268 & 48.29 \\
\hline & 6 th $\sim 10$ th & 127 & 22.88 \\
\hline & 11 th $\sim 15$ th & 98 & 17.66 \\
\hline & 16 th $\sim 25$ th & 55 & 9.91 \\
\hline & No answer & 7 & 1.26 \\
\hline \multirow{6}{*}{$\begin{array}{c}\text { Construction } \\
\text { completion } \\
\text { year }\end{array}$} & Before 1990 & 42 & 7.57 \\
\hline & $1990 \sim 1995$ & 120 & 21.62 \\
\hline & $1996 \sim 2000$ & 169 & 30.45 \\
\hline & $2001 \sim 2005$ & 74 & 13.33 \\
\hline & $2006 \sim 2010$ & 94 & 16.94 \\
\hline & Not sure & 56 & 10.09 \\
\hline
\end{tabular}

준공년도는 1996 2000년도가 30.4\%로 가장 많 았고, 1990 1995년도가 그 다음으로 $21.6 \%$ 를 차 지했다. 준공년도를 모르는 응답자는 주로 오래된 주택이나 원룸 거주자로 $10.1 \%$ 가 응답했다.

\section{2 외부소음환경에 대한 조사 결과}

Table 3은 거주지의 외부소음환경에 대한 만족도 를 선행연구와 비교한 것이다. 1986년과 1996년의

Table 3 Satisfaction with outdoor noise

\begin{tabular}{c|c|c|c}
\hline \hline Year surveyed & $1986^{(2)}$ & $1996^{(5)}$ & 2010 \\
\hline $\begin{array}{c}\text { Degree of } \\
\text { satisfaction }\end{array}$ & $39.3 \%$ & $69.5 \%$ & $57.1 \%$ \\
\hline
\end{tabular}

Table 4 Annoyance of outdoor noise in living

\begin{tabular}{|c|c|c|c|c|c|c|}
\hline \multirow[b]{2}{*}{$\begin{array}{l}\text { Degree of } \\
\text { annoyance }\end{array}$} & \multicolumn{6}{|c|}{ Rate of annoyance for the activities $(\%)$} \\
\hline & $\begin{array}{l}\mathrm{TV}, \\
\text { radio }\end{array}$ & $\begin{array}{l}\text { Reading, } \\
\text { concen- } \\
\text { tration }\end{array}$ & Relax & $\begin{array}{c}\text { Sleep- } \\
\text { ing }\end{array}$ & $\begin{array}{c}\text { Speaking } \\
\text { phone } \\
\text { call }\end{array}$ & Work \\
\hline \multirow{4}{*}{$\begin{array}{l}\text { Not at } \\
\text { all }\end{array}$} & 20.2 & 14.6 & 15.7 & 13.9 & 23.1 & 26.7 \\
\hline & 24.3 & 17.1 & 15.0 & 16.9 & 21.6 & 20.7 \\
\hline & 16.8 & 9.9 & 11.9 & 13.0 & 14.1 & 15.1 \\
\hline & 15.3 & 15.0 & 13.2 & 9.2 & 18.7 & 13.9 \\
\hline \multirow{3}{*}{$\begin{array}{l}\text { Very } \\
\text { much }\end{array}$} & 11.5 & 12.3 & 14.1 & 12.8 & 10.5 & 10.5 \\
\hline & 6.8 & 14.1 & 13.5 & 14.4 & 7.0 & 7.2 \\
\hline & 5.0 & 17.1 & 16.8 & 19.8 & 5.0 & 5.9 \\
\hline Total & 100.0 & 100.0 & 100.0 & 100.0 & 100.0 & 100.0 \\
\hline
\end{tabular}

Table 5 Response to outdoor noise

\begin{tabular}{l|c|c|c|c}
\hline \multirow{2}{*}{\multicolumn{1}{c|}{ Item }} & \multicolumn{2}{c|}{$\begin{array}{c}\text { Frequency } \\
(\mathrm{N})\end{array}$} & \multicolumn{2}{c}{$\begin{array}{c}\text { Percentage } \\
(\%)\end{array}$} \\
\cline { 2 - 5 } & Mean & Stdev* & Mean & Stdev* \\
\hline Road traffic noise & 3.57 & 1.85 & 3.55 & 1.94 \\
\hline Railway noise & 1.29 & 0.92 & 2.05 & 1.78 \\
\hline Aircraft noise & 1.73 & 1.33 & 2.36 & 1.97 \\
\hline $\begin{array}{l}\text { Machinery sound from } \\
\text { factory }\end{array}$ & 1.30 & 0.95 & 2.18 & 1.86 \\
\hline Constructing sound & 1.78 & 1.34 & 2.63 & 2.05 \\
\hline Blasting sound & 1.27 & 0.83 & 2.25 & 2.00 \\
\hline Sale of street vendors & 3.02 & 1.66 & 3.43 & 2.01 \\
\hline Neighboring store & 2.25 & 1.59 & 2.97 & 2.00 \\
\hline $\begin{array}{l}\text { Children playing } \\
\text { Sound by animal like } \\
\text { bird's chirping, dog's } \\
\text { barking }\end{array}$ & 2.45 & 1.69 & 3.28 & 1.86 \\
\hline * Stdev : standard deviation(the same after this) \\
\hline
\end{tabular}


결과를 비교하면 만족도가 크게 향상되어 외부소음 환경이 상당히 개선되었음을 알 수 있다. 반면 2010년에는 만족도가 다소 감소되었는데, 1996년 이후 외부소음환경은 거주민의 정온한 환경에 대한
관심과 욕구의 증가에 비해 상대적으로 많이 개선 되지 못한 것에 의한 결과로 사료된다.

하루 중 외부소음이 가장 시끄럽게 느껴지는 시간 은 저녁시간(19:00 22:00)이 $37.7 \%$, 오후시간(12:00

Table 6 Significance of subjective response to outdoor noise

\begin{tabular}{|c|c|c|c|c|c|c|c|c|c|c|c|c|}
\hline \multicolumn{3}{|c|}{ Item } & \multicolumn{5}{|c|}{ Frequency mean(standard deviation) } & \multicolumn{5}{|c|}{ Annoyance mean(standard deviation) } \\
\hline \multicolumn{2}{|l|}{ Variable } & $\mathrm{N}$ & $\begin{array}{c}\text { Road } \\
\text { traffic } \\
\text { noise }\end{array}$ & $\begin{array}{l}\text { Sale of } \\
\text { street } \\
\text { vendors }\end{array}$ & $\begin{array}{l}\text { Neighbor } \\
\text { ing store }\end{array}$ & $\begin{array}{l}\text { Children } \\
\text { playing }\end{array}$ & $\begin{array}{c}\text { Animal } \\
\text { like bird } \\
\text { or dog }\end{array}$ & $\begin{array}{c}\text { Road } \\
\text { traffic } \\
\text { noise }\end{array}$ & $\begin{array}{l}\text { Sale of } \\
\text { street } \\
\text { vendors }\end{array}$ & $\begin{array}{l}\text { Neighbor } \\
\text { ing store }\end{array}$ & $\begin{array}{c}\text { Children } \\
\text { playing }\end{array}$ & $\begin{array}{l}\text { Animal } \\
\text { like bird } \\
\text { or dog }\end{array}$ \\
\hline \multirow{3}{*}{$\begin{array}{l}\text { Type of } \\
\text { house }\end{array}$} & Single house & 89 & $\begin{array}{c}3.72 \\
(1.86)\end{array}$ & $\begin{array}{c}3.57 \\
(1.70)\end{array}$ & $\begin{array}{c}2.38 \\
(1.62)\end{array}$ & $\begin{array}{c}3.67 \\
(1.49)\end{array}$ & $\begin{array}{c}3.13 \\
(1.57)\end{array}$ & $\begin{array}{c}3.83 \\
(1.93)\end{array}$ & $\begin{array}{c}3.98 \\
(1.76)\end{array}$ & $\begin{array}{c}3.29 \\
(2.03)\end{array}$ & $\begin{array}{c}3.58 \\
(1.64)\end{array}$ & $\begin{array}{c}2.83 \\
(1.69)\end{array}$ \\
\hline & $\begin{array}{l}\text { Apartment } \\
\text { or row } \\
\text { house }\end{array}$ & 431 & $\begin{array}{c}3.53 \\
(1.83)\end{array}$ & $\begin{array}{c}2.94 \\
(1.62)\end{array}$ & $\begin{array}{c}2.23 \\
(1.56)\end{array}$ & $\begin{array}{c}3.45 \\
(1.72)\end{array}$ & $\begin{array}{c}2.45 \\
(1.52)\end{array}$ & $\begin{array}{c}3.50 \\
(1.92)\end{array}$ & $\begin{array}{c}3.36 \\
(2.03)\end{array}$ & $\begin{array}{c}2.92 \\
(1.99)\end{array}$ & $\begin{array}{c}3.27 \\
(1.90)\end{array}$ & $\begin{array}{c}2.42 \\
(1.68)\end{array}$ \\
\hline & t-value & & 0.879 & 3.348 & $\underset{* 844}{* * * *}$ & 1.132 & $\begin{array}{c}3.869 \\
* * * *\end{array}$ & 1.495 & $\underset{* *}{2.648}$ & 1.587 & 1.468 & $\begin{array}{c}2.094 \\
*\end{array}$ \\
\hline \multirow{6}{*}{$\begin{array}{l}\text { Period } \\
\text { of } \\
\text { residence } \\
\text { (only for } \\
\text { the } \\
\text { APT } \\
\text { residents) }\end{array}$} & $\begin{array}{c}\text { Below } 1 \\
\text { year }\end{array}$ & 83 & $\begin{array}{c}3.47 \\
(1.86)\end{array}$ & $\begin{array}{c}2.92 \\
(1.68) \\
\end{array}$ & $\begin{array}{c}2.49 \\
(1.88)\end{array}$ & $\begin{array}{c}3.43 \\
(1.82) \\
\end{array}$ & $\begin{array}{c}2.43 \\
(1.62)\end{array}$ & $\begin{array}{c}3.82 \\
(1.93) \\
\end{array}$ & $\begin{array}{c}3.77 \\
(2.14)\end{array}$ & $\begin{array}{c}3.34 \\
(2.20) \\
\end{array}$ & $\begin{array}{c}3.53 \\
(2.04) \\
\end{array}$ & \\
\hline & $1 \sim 3$ years & 140 & $\begin{array}{c}3.6 \\
(1.83)\end{array}$ & $\begin{array}{c}2.97 \\
(1.55)\end{array}$ & $\begin{array}{c}2.12 \\
(1.40)\end{array}$ & $\begin{array}{c}3.46 \\
(1.70)\end{array}$ & $\begin{array}{c}2.41 \\
(1.47)\end{array}$ & $\begin{array}{c}3.46 \\
(1.86)\end{array}$ & $\begin{array}{c}3.22 \\
(2.03)\end{array}$ & $\begin{array}{c}2.88 \\
(1.88)\end{array}$ & $\begin{array}{c}3.24 \\
(1.80)\end{array}$ & \\
\hline & $4 \sim 5$ years & 76 & $\begin{array}{c}3.42 \\
(1.86)\end{array}$ & $\begin{array}{c}2.75 \\
(1.70)\end{array}$ & $\begin{array}{c}2.04 \\
(1.58)\end{array}$ & $\begin{array}{c}3.3 \\
(1.67)\end{array}$ & $\begin{array}{c}2.2 \\
(1.47)\end{array}$ & $\begin{array}{c}3.32 \\
(2.09) \\
\end{array}$ & $\begin{array}{c}3.3 \\
(2.12)\end{array}$ & $\begin{array}{l}2.66 \\
(1.94)\end{array}$ & $\begin{array}{c}3.04 \\
(1.88)\end{array}$ & \\
\hline & $6 \sim 10$ years & 86 & $\begin{array}{c}3.6 \\
(1.82)\end{array}$ & $\begin{array}{c}3.05 \\
(1.69)\end{array}$ & & $\begin{array}{c}3.5 \\
(1.64)\end{array}$ & $\begin{array}{c}2.6 \\
(1.47)\end{array}$ & $\begin{array}{c}3.57 \\
(1.94)\end{array}$ & $\begin{array}{c}3.33 \\
(1.95)\end{array}$ & $\begin{array}{c}3.07 \\
(1.99)\end{array}$ & $\begin{array}{c}3.27 \\
(1.86)\end{array}$ & $\begin{array}{c}2.3 \\
(1.47)\end{array}$ \\
\hline & $\begin{array}{c}\text { More than } \\
10 \text { years }\end{array}$ & 46 & $\begin{array}{c}3.48 \\
(1.79)\end{array}$ & $\begin{array}{c}2.96 \\
(1.53)\end{array}$ & $\begin{array}{c}2.02 \\
(1.39)\end{array}$ & $\begin{array}{c}3.61 \\
(1.84) \\
\end{array}$ & $\begin{array}{c}2.7 \\
(1.64)\end{array}$ & $\begin{array}{c}3.2 \\
(1.76)\end{array}$ & $\begin{array}{c}3.24 \\
(1.84)\end{array}$ & $\begin{array}{c}2.48 \\
(1.89) \\
\end{array}$ & $\begin{array}{c}3.26 \\
(2.06) \\
\end{array}$ & $\begin{array}{c}2.2 \\
(1.64)\end{array}$ \\
\hline & F-value & & 0.185 & 0.368 & 1.566 & 0.258 & 1.075 & 1.081 & 1.073 & 1.966 & 0.679 & 0.473 \\
\hline \multirow{5}{*}{$\begin{array}{c}\text { Ownership } \\
\text { (only for } \\
\text { the } \\
\text { APT } \\
\text { residents) }\end{array}$} & $\begin{array}{c}\text { Private } \\
\text { residence }\end{array}$ & 263 & $\begin{array}{c}3.61 \\
(1.85) \\
\end{array}$ & $\begin{array}{c}2.84 \\
(1.60) \\
\end{array}$ & $\begin{array}{c}2.22 \\
(1.57)\end{array}$ & $\begin{array}{c}3.35 \\
(1.64) \\
\end{array}$ & $\begin{array}{c}2.44 \\
(1.48)\end{array}$ & $\begin{array}{c}3.55 \\
(1.95) \\
\end{array}$ & $\begin{array}{c}3.26 \\
(1.95)\end{array}$ & $\begin{array}{c}2.85 \\
(1.96)\end{array}$ & $\begin{array}{c}3.17 \\
(1.83) \\
\end{array}$ & $\begin{array}{c}2.34 \\
(1.50)\end{array}$ \\
\hline & $\begin{array}{c}\text { Lease on a } \\
\text { deposit basis }\end{array}$ & 108 & $\begin{array}{c}3.43 \\
(1.78) \\
\end{array}$ & $\begin{array}{c}3.01 \\
(1.63) \\
\end{array}$ & $\begin{array}{c}2.12 \\
(1.41)\end{array}$ & $\begin{array}{c}3.56 \\
(1.74) \\
\end{array}$ & $\begin{array}{c}2.45 \\
(1.50)\end{array}$ & $\begin{array}{c}3.44 \\
(1.93) \\
\end{array}$ & $\begin{array}{c}3.48 \\
(2.13)\end{array}$ & $\begin{array}{c}3.01 \\
(2.01)\end{array}$ & $\begin{array}{c}3.44 \\
(2.00)\end{array}$ & $\begin{array}{c}2.56 \\
(1.90) \\
\end{array}$ \\
\hline & Lease & 28 & $\begin{array}{c}3.36 \\
(1.75) \\
\end{array}$ & $\begin{array}{c}2.57 \\
(1.62) \\
\end{array}$ & $\begin{array}{c}2.07 \\
(1.44) \\
\end{array}$ & $\begin{array}{c}3.32 \\
(2.06) \\
\end{array}$ & $\begin{array}{c}2.25 \\
(1.69) \\
\end{array}$ & $\begin{array}{r}3.29 \\
(1.63) \\
\end{array}$ & $\begin{array}{c}3.07 \\
(2.21) \\
\end{array}$ & $\begin{array}{c}2.39 \\
(1.81)\end{array}$ & $\begin{array}{c}3.21 \\
(1.99)\end{array}$ & $\begin{array}{c}2.29 \\
(1.88) \\
\end{array}$ \\
\hline & $\begin{array}{c}\text { Monthly } \\
\text { rent }\end{array}$ & 30 & $\begin{array}{c}3.33 \\
(1.77) \\
\end{array}$ & $\begin{array}{c}3.87 \\
(1.53) \\
\end{array}$ & $\begin{array}{c}2.83 \\
(2.04)\end{array}$ & $\begin{array}{c}4.13 \\
(1.89) \\
\end{array}$ & $\begin{array}{c}2.63 \\
(1.79) \\
\end{array}$ & $\begin{array}{c}3.4 \\
(1.87)\end{array}$ & $\begin{array}{c}4.1 \\
(2.01)\end{array}$ & $\begin{array}{c}3.67 \\
(2.09)\end{array}$ & $\begin{array}{c}3.53 \\
(1.96)\end{array}$ & $\begin{array}{l}2.73 \\
(2.05)\end{array}$ \\
\hline & F-value & & 0.495 & $\underset{* *}{4.262}$ & 1.776 & 2.105 & 0.309 & 0.245 & 1.882 & 2.278 & 0.732 & 0.887 \\
\hline \multirow{6}{*}{$\begin{array}{c}\text { Construction } \\
\text { completion } \\
\text { year } \\
\text { (only for } \\
\text { the } \\
\text { APT } \\
\text { residents) }\end{array}$} & Before 1990 & 19 & $\begin{array}{c}3.63 \\
(1.92) \\
\end{array}$ & $\begin{array}{c}3.84 \\
(2.12) \\
\end{array}$ & $\begin{array}{c}2.32 \\
(1.45)\end{array}$ & $\begin{array}{c}3.89 \\
(1.85) \\
\end{array}$ & $\begin{array}{c}2.84 \\
(1.77) \\
\end{array}$ & $\begin{array}{c}3.95 \\
(2.01) \\
\end{array}$ & $\begin{array}{c}3.95 \\
(2.44) \\
\end{array}$ & $\begin{array}{c}3.16 \\
(2.06) \\
\end{array}$ & $\begin{array}{c}3.47 \\
(2.09) \\
\end{array}$ & $\begin{array}{c}2.47 \\
(1.74) \\
\end{array}$ \\
\hline & $1990 \sim 1995$ & 83 & $\begin{array}{c}3.48 \\
(1.86)\end{array}$ & $\begin{array}{c}2.87 \\
(1.59)\end{array}$ & $\begin{array}{c}2.17 \\
(1.49)\end{array}$ & $\begin{array}{c}3.3 \\
(1.57)\end{array}$ & $\begin{array}{c}2.37 \\
(1.45)\end{array}$ & $\begin{array}{c}3.75 \\
(1.91)\end{array}$ & $\begin{array}{c}3.45 \\
(2.03)\end{array}$ & $\begin{array}{c}3.06 \\
(2.12)\end{array}$ & $\begin{array}{c}3.23 \\
(1.90)\end{array}$ & $\begin{array}{c}2.37 \\
(1.67)\end{array}$ \\
\hline & 1996 2000 & 111 & $\begin{array}{c}3.61 \\
(1.83)\end{array}$ & $\begin{array}{c}3.23 \\
(1.53)\end{array}$ & $\begin{array}{c}2.47 \\
(1.70)\end{array}$ & $\begin{array}{c}3.43 \\
(1.67)\end{array}$ & $\begin{array}{c}2.53 \\
(1.50)\end{array}$ & $\begin{array}{c}3.67 \\
(1.89)\end{array}$ & $\begin{array}{c}3.67 \\
(1.81)\end{array}$ & $\begin{array}{c}3.21 \\
(1.88)\end{array}$ & $\begin{array}{c}3.25 \\
(1.74)\end{array}$ & $\begin{array}{c}2.46 \\
(1.48)\end{array}$ \\
\hline & $2001 \sim 2005$ & 60 & $\begin{array}{c}3.72 \\
(1.89)\end{array}$ & $\begin{array}{c}2.65 \\
(1.38)\end{array}$ & $\begin{array}{c}2.18 \\
(1.51)\end{array}$ & $\begin{array}{c}3.52 \\
(1.78)\end{array}$ & $\begin{array}{c}2.47 \\
(1.42)\end{array}$ & $\begin{array}{c}3.37 \\
(1.93)\end{array}$ & $\begin{array}{c}3.23 \\
(2.09)\end{array}$ & $\begin{array}{l}2.97 \\
(2.05)\end{array}$ & $\begin{array}{c}3.37 \\
(1.88)\end{array}$ & $\begin{array}{c}2.4 \\
(1.69)\end{array}$ \\
\hline & $2006 \sim 2010$ & 78 & $\begin{array}{c}3.5 \\
(1.91)\end{array}$ & $\begin{array}{c}2.77 \\
(1.84)\end{array}$ & $\begin{array}{c}2.13 \\
(1.64)\end{array}$ & $\begin{array}{c}3.4 \\
(1.98)\end{array}$ & $\begin{array}{c}2.41 \\
(1.57)\end{array}$ & $\begin{array}{c}3.53 \\
(2.12)\end{array}$ & $\begin{array}{c}3.26 \\
(2.35)\end{array}$ & $\begin{array}{l}2.88 \\
(2.17)\end{array}$ & $\begin{array}{c}3.53 \\
(2.22)\end{array}$ & $\begin{array}{c}2.6 \\
(1.98)\end{array}$ \\
\hline & F-value & & 0.185 & 3.049 & 0.714 & 0.491 & 0.452 & 0.530 & 0.905 & 0.330 & 0.331 & 0.211 \\
\hline
\end{tabular}

1. ${ }^{*} \mathrm{P}<.05, * * \mathrm{P}<.01, * * * \mathrm{P}<.001$

2. data that is not responded nor sure were excluded. 
19:00)이 $25.4 \%$ 를 나타내어 2007년 조사 결과 ${ }^{(6)}$ 와 같이 주택 내에서 생활이 많이 이루어지는 시간에 외부소음에 의한 영향을 가장 많이 받는 것으로 나 타났다.

또한 라디오 청취 및 $\mathrm{TV}$ 시청, 독서 또는 정신 집중, 휴식, 수면, 대화나 전화 통화, 기타 작업 등 실내 활동의 종류에 따른 외부소음에 의한 방해 정 도를 7단계 양극 척도로 조사한 결과, 독서 또는 정신집중, 휴식, 수면 등의 정적인 활동의 소음에 의한 방해 정도가 작업 등과 같은 동적인 활동에

Table 7 Response to indoor noise

\begin{tabular}{|c|c|c|c|c|c|}
\hline & \multirow{2}{*}{ Item } & \multicolumn{2}{|c|}{$\begin{array}{l}\text { Frequency } \\
(\mathrm{N})\end{array}$} & \multicolumn{2}{|c|}{$\begin{array}{c}\text { Percentage } \\
(\%)\end{array}$} \\
\hline & & Mean & Stdev & Mean & Stdev \\
\hline \multirow{6}{*}{$\begin{array}{l}\text { Impact } \\
\text { noise }\end{array}$} & $\begin{array}{c}\text { Entrance door } \\
\text { opening or closing }\end{array}$ & 3.29 & 1.89 & 3.05 & 1.90 \\
\hline & $\begin{array}{c}\text { Window opening or } \\
\text { closing }\end{array}$ & 2.16 & 1.52 & 2.35 & 1.68 \\
\hline & $\begin{array}{c}\text { Footsteps at } \\
\text { stairway or corridor }\end{array}$ & 3.18 & 1.81 & 3.02 & 1.85 \\
\hline & $\begin{array}{l}\text { Children jumping } \\
\text { and running }\end{array}$ & 3.30 & 2.03 & 3.46 & 2.08 \\
\hline & Footsteps in room & 2.83 & 1.80 & 2.77 & 1.84 \\
\hline & $\begin{array}{c}\text { Dropping small } \\
\text { stuff }\end{array}$ & 2.73 & 1.71 & 2.83 & 1.83 \\
\hline \multirow{6}{*}{$\begin{array}{l}\text { Plumbing } \\
\text { noise }\end{array}$} & $\begin{array}{l}\text { Plumbing by } \\
\text { bathtub }\end{array}$ & 3.27 & 1.86 & 2.92 & 1.86 \\
\hline & $\begin{array}{l}\text { Exhausting by } \\
\text { chamber pot }\end{array}$ & 3.11 & 1.83 & 2.91 & 1.87 \\
\hline & $\begin{array}{l}\text { Plumbing in the } \\
\text { kitchen }\end{array}$ & 2.57 & 1.62 & 2.45 & 1.64 \\
\hline & $\begin{array}{c}\text { Urinating in } \\
\text { bathroom }\end{array}$ & 2.83 & 1.78 & 2.79 & 1.84 \\
\hline & $\begin{array}{c}\text { Plumbing at } \\
\text { balcony }\end{array}$ & 2.67 & 1.71 & 2.56 & 1.74 \\
\hline & $\begin{array}{l}\text { Supplying water in } \\
\text { rooftop water tank }\end{array}$ & 1.77 & 1.32 & 1.95 & 1.41 \\
\hline Voice & Speaking & 2.44 & 1.53 & 2.57 & 1.63 \\
\hline \multirow{9}{*}{$\begin{array}{c}\text { Equip- } \\
\text { ment } \\
\text { noise }\end{array}$} & Elevator working & 2.26 & 1.60 & 2.32 & 1.65 \\
\hline & Doorbell & 2.63 & 1.69 & 2.55 & 1.67 \\
\hline & $\begin{array}{l}\text { Cooking in the } \\
\text { kitchen }\end{array}$ & 2.03 & 1.37 & 2.02 & 1.38 \\
\hline & $\mathrm{TV}$ or radio & 2.48 & 1.53 & 2.63 & 1.68 \\
\hline & $\begin{array}{c}\text { Musical instruments } \\
\text { like piano }\end{array}$ & 2.72 & 1.70 & 2.95 & 1.87 \\
\hline & Washing machine & 2.54 & 1.52 & 2.59 & 1.63 \\
\hline & Heating boiler & 2.06 & 1.32 & 2.19 & 1.48 \\
\hline & $\begin{array}{c}\text { Outdoor unit of air } \\
\text { conditioner }\end{array}$ & 1.98 & 1.35 & 2.14 & 1.51 \\
\hline & $\begin{array}{c}\text { Engine room at } \\
\text { basement }\end{array}$ & 1.52 & 1.07 & 1.77 & 1.36 \\
\hline
\end{tabular}

비해 높게 나타났다(Table 4). 따라서 현장 조사 및 청감 실험을 통한 소음에 대한 거주자의 반응 조사 시 활동의 종류에 대한 조건이 상당히 중요한 역할 을 할 것으로 사료된다.

주거 내에서의 다양한 활동에 영향을 미치는 외 부소음의 종류별 발생빈도를 조사하였으며, 그에 따 른 신경쓰임의 정도에 대해 조사한 결과를 Table 5 와 같이 정리하였다. 발생빈도와 신경쓰임 모두 도 로 교통 소음이 가장 높은 값을 나타냈다. 이는 주 택의 외부소음 차단을 위한 노력이 효과적으로 이 루어져야 하는 것을 보여준다. 발생빈도와 신경쓰임 정도를 비교해 볼 때, 도로교통소음은 비슷한 값을 보이고 있으며, 확성기소음 외부 영업장 소음은 발 생빈도에 비해 신경쓰임의 정도가 더 큰 반면 아이 들 떠드는 소리 및 새, 동물들 짖는 소리에 대해서 는 발생빈도에 비해 신경쓰임의 정도가 더 낮게 평 가되고 있다.

외부소음에 대한 발생빈도와 신경쓰임의 응답 평 균이 높게 나타난 상위 5 개 항목에 대해 $\mathrm{t}$-검증 및 $\mathrm{F}$-검증을 실시하여 주거의 특성에 따른 차이 여부를 분석하였다(Table 6). 주거 형태별 비교에서는 일반 주택과 아파트를 비교하였으나, 그 외의 거주기간,

Table 8 Unsatisfaction about indoor noise

\begin{tabular}{|c|c|c|c|c|}
\hline \multirow[b]{2}{*}{ Rank } & \multicolumn{4}{|c|}{ Year surveyed } \\
\hline & $1986^{(2)}$ & $1994^{(3)}$ & $1996^{(5)}$ & 2010 \\
\hline 1 & $\begin{array}{l}\text { Children } \\
\text { jumping and } \\
\text { running } \\
(46.7 \%)\end{array}$ & $\begin{array}{l}\text { Children } \\
\text { jumping and } \\
\text { running } \\
(51.1 \%)\end{array}$ & $\begin{array}{c}\text { Children } \\
\text { jumping and } \\
\text { running } \\
(58.4 \%)\end{array}$ & $\begin{array}{c}\text { Children } \\
\text { jumping and } \\
\text { running } \\
(48.1 \%)\end{array}$ \\
\hline 2 & $\begin{array}{c}\text { Plumbing by } \\
\text { bathtub }\end{array}$ & $\begin{array}{c}\begin{array}{c}\text { Exhausting } \\
\text { by chamber } \\
\text { pot }\end{array} \\
(50.9 \%)\end{array}$ & $\begin{array}{c}\text { Plumbing by } \\
\text { bathtub }\end{array}$ & $\begin{array}{l}\text { Entrance } \\
\text { door } \\
\text { opening or } \\
\text { closing } \\
(47.0 \%) \\
\end{array}$ \\
\hline 3 & $\begin{array}{c}\text { Footsteps at } \\
\text { stairway or } \\
\text { corridor } \\
(41.4 \%)\end{array}$ & $\begin{array}{c}\begin{array}{c}\text { Plumbing by } \\
\text { bathtub }\end{array} \\
(49.7 \%)\end{array}$ & $\begin{array}{c}\text { Exhausting } \\
\text { by chamber } \\
\text { pot } \\
(49.5 \%)\end{array}$ & $\begin{array}{c}\begin{array}{c}\text { Plumbing by } \\
\text { bathtub }\end{array} \\
(46.6 \%)\end{array}$ \\
\hline 4 & $\begin{array}{c}\text { Exhausting } \\
\text { by chamber } \\
\text { pot } \\
(38.6 \%)\end{array}$ & $\begin{array}{l}\text { Elevator } \\
\text { working } \\
(45.2 \%)\end{array}$ & $\begin{array}{c}\begin{array}{c}\text { Plumbing at } \\
\text { balcony }\end{array} \\
(39.5 \%)\end{array}$ & $\begin{array}{c}\text { Exhausting } \\
\text { by chamber } \\
\text { pot } \\
(45.0 \%)\end{array}$ \\
\hline 5 & \begin{tabular}{|c|} 
Entrance \\
door opening \\
or closing \\
$(32.9 \%)$ \\
\end{tabular} & $\begin{array}{c}\begin{array}{c}\text { Plumbing at } \\
\text { balcony }\end{array} \\
(41.3 \%)\end{array}$ & $\begin{array}{c}\text { Musical } \\
\text { instruments } \\
\text { like piano } \\
(33.8 \%)\end{array}$ & $\begin{array}{c}\text { Footsteps at } \\
\text { stairway or } \\
\text { corridor } \\
(44.9 \%)\end{array}$ \\
\hline 6 & $\begin{array}{c}\text { Discarding } \\
\text { garbage } \\
(31.1 \%)\end{array}$ & $\begin{array}{c}\text { Musical } \\
\text { instruments } \\
\text { like piano } \\
(36.1 \%)\end{array}$ & $\begin{array}{c}\text { Entrance } \\
\text { door opening } \\
\text { or closing } \\
(29.9 \%)\end{array}$ & $\begin{array}{c}\text { Exhausting } \\
\text { by chamber } \\
\text { pot } \\
(41.7 \%)\end{array}$ \\
\hline
\end{tabular}


입주방식, 준공년도에 대해서는 아파트 거주자만을 대상으로 분석하였다. 단독 주택의 경우 응답자 수
에 비해 고려해야 할 변수가 많아 통계적인 분석이 어려울 것이라 판단하였기 때문이다. 그 결과 주거

Table 9 Significance of subjective response to indoor noise

\begin{tabular}{|c|c|c|c|c|c|c|c|c|c|c|c|c|}
\hline \multirow{3}{*}{ Variable } & \multirow{3}{*}{ Item } & \multirow{3}{*}{$\mathrm{N}$} & \multicolumn{5}{|c|}{ Frequency mean(standard deviation) } & \multicolumn{5}{|c|}{ Annoyance mean(standard deviation) } \\
\hline & & & $\begin{array}{c}\text { Children } \\
\text { jumping } \\
\text { and } \\
\text { running }\end{array}$ & $\begin{array}{c}\text { Entrance } \\
\text { door } \\
\text { opening } \\
\text { or closing }\end{array}$ & $\begin{array}{c}\text { Plumbing } \\
\text { by } \\
\text { bathtub }\end{array}$ & $\begin{array}{c}\text { Exhausting } \\
\text { by } \\
\text { chamber } \\
\text { pot }\end{array}$ & \begin{tabular}{|l||} 
Footsteps \\
at \\
stairway \\
or \\
corridor \\
\end{tabular} & $\begin{array}{c}\text { Children } \\
\text { jumping } \\
\text { and } \\
\text { running }\end{array}$ & $\begin{array}{c}\text { Entrance } \\
\text { door } \\
\text { opening } \\
\text { or closing }\end{array}$ & $\begin{array}{c}\text { Plumbing } \\
\text { by } \\
\text { bathtub }\end{array}$ & \begin{tabular}{|} 
Exhausting \\
by \\
chamber \\
pot
\end{tabular} & $\begin{array}{c}\text { Footsteps } \\
\text { at } \\
\text { stairway } \\
\text { or } \\
\text { corridor }\end{array}$ \\
\hline & & & $\begin{array}{c}\mathrm{M} \\
(\mathrm{SD})\end{array}$ & $\begin{array}{c}\mathrm{M} \\
(\mathrm{SD})\end{array}$ & $\begin{array}{c}\mathrm{M} \\
(\mathrm{SD})\end{array}$ & $\begin{array}{c}\mathrm{M} \\
(\mathrm{SD})\end{array}$ & $\begin{array}{c}\mathrm{M} \\
(\mathrm{SD})\end{array}$ & $\begin{array}{c}\mathrm{M} \\
(\mathrm{SD})\end{array}$ & $\begin{array}{c}\mathrm{M} \\
(\mathrm{SD})\end{array}$ & $\begin{array}{c}\mathrm{M} \\
(\mathrm{SD})\end{array}$ & $\begin{array}{c}\mathrm{M} \\
(\mathrm{SD})\end{array}$ & $\begin{array}{c}\mathrm{M} \\
(\mathrm{SD})\end{array}$ \\
\hline \multirow{3}{*}{$\begin{array}{c}\text { Type of } \\
\text { house }\end{array}$} & $\begin{array}{l}\text { Single } \\
\text { house }\end{array}$ & 89 & $\begin{array}{c}2.35 \\
(1.80)\end{array}$ & $\begin{array}{c}2.90 \\
(2.00)\end{array}$ & $\begin{array}{c}2.61 \\
(1.97)\end{array}$ & $\begin{array}{c}2.48 \\
(1.85)\end{array}$ & $\begin{array}{c}2.61 \\
(1.70)\end{array}$ & $\begin{array}{c}2.45 \\
(1.73)\end{array}$ & $\begin{array}{c}2.69 \\
(1.81)\end{array}$ & $\begin{array}{c}2.45 \\
(1.75)\end{array}$ & $\begin{array}{c}2.38 \\
(1.77)\end{array}$ & $\begin{array}{c}2.53 \\
(1.69) \\
\end{array}$ \\
\hline & $\begin{array}{l}\text { Apart- } \\
\text { ment } \\
\text { or row } \\
\text { house }\end{array}$ & 431 & $\begin{array}{c}3.59 \\
(2.00)\end{array}$ & $\begin{array}{c}3.37 \\
(1.85)\end{array}$ & $\begin{array}{c}3.47 \\
(1.85)\end{array}$ & $\begin{array}{c}3.30 \\
(1.81)\end{array}$ & $\begin{array}{l}3.27 \\
(1.77)\end{array}$ & $\begin{array}{c}3.76 \\
(2.08)\end{array}$ & $\begin{array}{c}3.11 \\
(1.90)\end{array}$ & $\begin{array}{r}3.06 \\
(1.87)\end{array}$ & $\begin{array}{r}3.04 \\
(1.89)\end{array}$ & $\begin{array}{c}3.13 \\
(1.86)\end{array}$ \\
\hline & T-value & & $\begin{array}{c}5.447 \\
*\end{array}$ & 2.176 & 4.079 & 3.883 & 3.236 & $\begin{array}{c}5.581 \\
* * *\end{array}$ & 1.963 & 2.834 & $\begin{array}{c}3.076 \\
*\end{array}$ & $\begin{array}{c}2.819 \\
*\end{array}$ \\
\hline \multirow{6}{*}{$\begin{array}{l}\text { Period of } \\
\text { residence } \\
\text { (only for } \\
\text { the } \\
\text { APT } \\
\text { residents) }\end{array}$} & $\begin{array}{c}\text { Below } 1 \\
\text { year }\end{array}$ & 83 & $\begin{array}{c}3.78 \\
(2.17) \\
\end{array}$ & $\begin{array}{c}3.13 \\
(1.96) \\
\end{array}$ & $\begin{array}{c}3.59 \\
(1.85) \\
\end{array}$ & $\begin{array}{c}3.33 \\
(1.89) \\
\end{array}$ & $\begin{array}{c}3.16 \\
(1.84) \\
\end{array}$ & $\begin{array}{c}3.94 \\
(2.23) \\
\end{array}$ & $\begin{array}{c}3.10 \\
(1.96) \\
\end{array}$ & $\begin{array}{c}3.28 \\
(2.02) \\
\end{array}$ & $\begin{array}{c}3.23 \\
(2.07) \\
\end{array}$ & $\begin{array}{c}3.18 \\
(1.90) \\
\end{array}$ \\
\hline & $\begin{array}{c}1 \sim 3 \\
\text { years }\end{array}$ & 140 & $\begin{array}{c}3.48 \\
(1.97) \\
\end{array}$ & $\begin{array}{c}3.64 \\
(1.85)\end{array}$ & $\begin{array}{c}3.45 \\
(1.87) \\
\end{array}$ & $\begin{array}{c}3.29 \\
(1.77) \\
\end{array}$ & $\begin{array}{c}3.46 \\
(1.88) \\
\end{array}$ & $\begin{array}{c}3.61 \\
(2.07)\end{array}$ & $\begin{array}{c}3.34 \\
(1.97)\end{array}$ & $\begin{array}{c}2.96 \\
(1.79)\end{array}$ & $\begin{array}{c}3.02 \\
(1.79)\end{array}$ & $\begin{array}{c}3.22 \\
(1.95)\end{array}$ \\
\hline & $\begin{array}{c}4 \sim 5 \\
\text { years }\end{array}$ & 76 & $\begin{array}{c}3.55 \\
(1.91) \\
\end{array}$ & $\begin{array}{c}3.05 \\
(1.72) \\
\end{array}$ & $\begin{array}{c}3.55 \\
(1.92) \\
\end{array}$ & $\begin{array}{c}3.36 \\
(1.84) \\
\end{array}$ & $\begin{array}{c}3.24 \\
(1.60)\end{array}$ & $\begin{array}{c}3.68 \\
(1.91) \\
\end{array}$ & $\begin{array}{c}2.80 \\
(1.93) \\
\end{array}$ & $\begin{array}{c}3.25 \\
(1.86) \\
\end{array}$ & $\begin{array}{c}3.11 \\
(1.82) \\
\end{array}$ & $\begin{array}{c}3.04 \\
(1.91) \\
\end{array}$ \\
\hline & $\begin{array}{l}6 \sim 10 \\
\text { years }\end{array}$ & 86 & $\begin{array}{c}3.56 \\
(1.92) \\
\end{array}$ & $\begin{array}{c}3.34 \\
(1.78) \\
\end{array}$ & $\begin{array}{c}3.47 \\
(1.77) \\
\end{array}$ & $\begin{array}{c}3.37 \\
(1.88) \\
\end{array}$ & $\begin{array}{c}3.16 \\
(1.69) \\
\end{array}$ & $\begin{array}{c}3.81 \\
(2.09) \\
\end{array}$ & $\begin{array}{c}3.10 \\
(1.82) \\
\end{array}$ & $\begin{array}{c}3.10 \\
(1.95) \\
\end{array}$ & $\begin{array}{c}3.09 \\
(2.05) \\
\end{array}$ & $\begin{array}{c}3.10 \\
(1.83) \\
\end{array}$ \\
\hline & $\begin{array}{c}\text { More } \\
\text { than } 10 \\
\text { years }\end{array}$ & 46 & $\begin{array}{c}3.74 \\
(2.08)\end{array}$ & $\begin{array}{c}3.61 \\
(1.95)\end{array}$ & $\begin{array}{c}3.22 \\
(1.86)\end{array}$ & $\begin{array}{c}3.04 \\
(1.69)\end{array}$ & $\begin{array}{c}3.15 \\
(1.70)\end{array}$ & $\begin{array}{c}3.87 \\
(2.16)\end{array}$ & $\begin{array}{c}3.00 \\
(1.67)\end{array}$ & $\begin{array}{c}2.57 \\
(1.70)\end{array}$ & $\begin{array}{c}2.57 \\
(1.64)\end{array}$ & $\begin{array}{c}2.93 \\
(1.54)\end{array}$ \\
\hline & F-value & & 0.377 & 1.826 & 0.342 & 0.286 & 0.643 & 0.395 & 1.030 & 1.397 & 0.972 & 0.272 \\
\hline \multirow{5}{*}{$\begin{array}{l}\text { Ownership } \\
\text { (only for } \\
\text { the } \\
\text { APT } \\
\text { residents) }\end{array}$} & $\begin{array}{c}\text { Private } \\
\text { residence }\end{array}$ & 263 & $\begin{array}{c}3.62 \\
(1.94) \\
\end{array}$ & $\begin{array}{c}3.25 \\
(1.78) \\
\end{array}$ & $\begin{array}{c}3.45 \\
(1.79) \\
\end{array}$ & $\begin{array}{c}3.31 \\
(1.80) \\
\end{array}$ & $\begin{array}{c}3.09 \\
(1.64) \\
\end{array}$ & $\begin{array}{c}3.75 \\
(2.03) \\
\end{array}$ & $\begin{array}{c}3.03 \\
(1.81) \\
\end{array}$ & $\begin{array}{c}3.09 \\
(1.87) \\
\end{array}$ & $\begin{array}{c}3.10 \\
(1.89) \\
\end{array}$ & $\begin{array}{c}3.00 \\
(1.77) \\
\end{array}$ \\
\hline & \begin{tabular}{|c|} 
Lease on \\
a depo- \\
sit basis
\end{tabular} & 108 & $\begin{array}{c}3.56 \\
(2.11) \\
\end{array}$ & $\begin{array}{c}3.55 \\
(1.86) \\
\end{array}$ & $\begin{array}{c}3.26 \\
(1.88) \\
\end{array}$ & $\begin{array}{c}3.23 \\
(1.77) \\
\end{array}$ & $\begin{array}{c}3.49 \\
(1.84) \\
\end{array}$ & $\begin{array}{c}3.75 \\
(2.16) \\
\end{array}$ & $\begin{array}{c}3.11 \\
(1.86) \\
\end{array}$ & $\begin{array}{c}2.83 \\
(1.78) \\
\end{array}$ & $\begin{array}{c}2.83 \\
(1.81) \\
\end{array}$ & $\begin{array}{c}3.22 \\
(1.87) \\
\end{array}$ \\
\hline & Lease & 28 & $\begin{array}{c}4.14 \\
(1.96) \\
\end{array}$ & $\begin{array}{c}3.39 \\
(2.18) \\
\end{array}$ & $\begin{array}{c}4.11 \\
(1.95) \\
\end{array}$ & $\begin{array}{c}3.32 \\
(1.83) \\
\end{array}$ & $\begin{array}{c}3.39 \\
(2.08) \\
\end{array}$ & $\begin{array}{c}3.82 \\
(2.33) \\
\end{array}$ & $\begin{array}{c}3.29 \\
(2.26) \\
\end{array}$ & $\begin{array}{c}3.32 \\
(1.93) \\
\end{array}$ & $\begin{array}{c}2.96 \\
(1.97) \\
\end{array}$ & $\begin{array}{c}3.18 \\
(2.13) \\
\end{array}$ \\
\hline & $\begin{array}{c}\text { Monthly } \\
\text { rent }\end{array}$ & 30 & $\begin{array}{c}3.07 \\
(2.03)\end{array}$ & $\begin{array}{c}3.93 \\
(2.10)\end{array}$ & $\begin{array}{c}3.93 \\
(2.05)\end{array}$ & $\begin{array}{c}3.53 \\
(2.10)\end{array}$ & $\begin{array}{c}4.03 \\
(2.06)\end{array}$ & $\begin{array}{c}3.73 \\
(2.05) \\
\end{array}$ & $\begin{array}{c}3.80 \\
(2.35)\end{array}$ & $\begin{array}{c}3.50 \\
(2.13)\end{array}$ & $\begin{array}{c}3.47 \\
(2.18)\end{array}$ & $\begin{array}{c}3.93 \\
(2.29) \\
\end{array}$ \\
\hline & F-value & & 1.432 & 1.612 & 2.224 & 0.219 & $\begin{array}{c}3.463 \\
*\end{array}$ & 0.011 & 1.537 & 1.279 & 1.032 & 2.397 \\
\hline \multirow{6}{*}{$\begin{array}{c}\text { Construction } \\
\text { completion } \\
\text { year } \\
\text { (only for } \\
\text { the } \\
\text { APT } \\
\text { residents) }\end{array}$} & $\begin{array}{c}\text { Before } \\
1990\end{array}$ & 19 & $\begin{array}{c}3.53 \\
(2.06)\end{array}$ & $\begin{array}{c}3.79 \\
(2.04)\end{array}$ & $\begin{array}{c}3.53 \\
(1.84)\end{array}$ & $\begin{array}{c}3.53 \\
(1.74)\end{array}$ & $\begin{array}{c}4.16 \\
(1.86)\end{array}$ & $\begin{array}{c}3.79 \\
(2.35)\end{array}$ & $\begin{array}{c}3.63 \\
(1.98) \\
\end{array}$ & $\begin{array}{c}3.05 \\
(1.99) \\
\end{array}$ & $\begin{array}{c}3.11 \\
(1.88)\end{array}$ & $\begin{array}{c}3.84 \\
(1.89) \\
\end{array}$ \\
\hline & $\begin{array}{c}1990 \sim \\
1995\end{array}$ & 83 & $\begin{array}{c}3.40 \\
(2.01)\end{array}$ & $\begin{array}{c}3.59 \\
(1.79)\end{array}$ & $\begin{array}{c}3.46 \\
(1.76) \\
\end{array}$ & $\begin{array}{c}3.30 \\
(1.69)\end{array}$ & $\begin{array}{c}3.36 \\
(1.72)\end{array}$ & $\begin{array}{c}3.51 \\
(2.10)\end{array}$ & $\begin{array}{c}3.25 \\
(1.83) \\
\end{array}$ & $\begin{array}{c}3.14 \\
(1.82)\end{array}$ & $\begin{array}{c}3.10 \\
(1.81)\end{array}$ & $\begin{array}{c}3.30 \\
(1.71)\end{array}$ \\
\hline & $\begin{array}{c}1996 \sim \\
2000\end{array}$ & 111 & $\begin{array}{c}3.60 \\
(1.93) \\
\end{array}$ & $\begin{array}{c}3.57 \\
(1.75) \\
\end{array}$ & $\begin{array}{c}3.86 \\
(1.92) \\
\end{array}$ & $\begin{array}{c}3.75 \\
(1.97) \\
\end{array}$ & $\begin{array}{c}3.47 \\
(1.68) \\
\end{array}$ & $\begin{array}{c}3.68 \\
(2.02) \\
\end{array}$ & $\begin{array}{c}3.42 \\
(1.96) \\
\end{array}$ & $\begin{array}{c}3.26 \\
(1.92) \\
\end{array}$ & $\begin{array}{c}3.41 \\
(1.98) \\
\end{array}$ & $\begin{array}{c}3.38 \\
(1.86) \\
\end{array}$ \\
\hline & $\begin{array}{l}2001 \sim \\
2005\end{array}$ & 60 & $\begin{array}{c}3.57 \\
(2.16) \\
\end{array}$ & $\begin{array}{c}3.33 \\
(1.86)\end{array}$ & $\begin{array}{c}3.25 \\
(1.95) \\
\end{array}$ & $\begin{array}{c}3.03 \\
(1.76) \\
\end{array}$ & $\begin{array}{c}3.12 \\
(1.73)\end{array}$ & $\begin{array}{c}3.80 \\
(2.22)\end{array}$ & $\begin{array}{c}2.98 \\
(1.78)\end{array}$ & $\begin{array}{c}2.88 \\
(1.98)\end{array}$ & $\begin{array}{c}2.93 \\
(1.97)\end{array}$ & $\begin{array}{c}3.05 \\
(1.84) \\
\end{array}$ \\
\hline & $\begin{array}{c}2006 \sim ~ \\
2010\end{array}$ & 78 & $\begin{array}{c}3.91 \\
(2.23) \\
\end{array}$ & $\begin{array}{c}2.92 \\
(2.07) \\
\end{array}$ & $\begin{array}{c}3.45 \\
(1.90) \\
\end{array}$ & $\begin{array}{c}3.19 \\
(1.87) \\
\end{array}$ & $\begin{array}{c}2.81 \\
(1.95) \\
\end{array}$ & $\begin{array}{c}4.03 \\
(2.35) \\
\end{array}$ & $\begin{array}{c}2.56 \\
(1.88)\end{array}$ & $\begin{array}{c}3.00 \\
(2.09)\end{array}$ & $\begin{array}{c}2.87 \\
(2.05)\end{array}$ & $\begin{array}{c}2.64 \\
(1.95)\end{array}$ \\
\hline & F-value & & 0.645 & 1.932 & 1.223 & 1.918 & $\begin{array}{c}3.043 \\
*\end{array}$ & 0.614 & $\begin{array}{c}2.955 \\
*\end{array}$ & 0.442 & 1.052 & $\begin{array}{c}2.752 \\
*\end{array}$ \\
\hline
\end{tabular}

1. $* \mathrm{P}<.05, * * \mathrm{P}<.01, * * * \mathrm{P}<.001$
2. data that is not responded nor sure were excluded. 
형태에 있어서는 대체적으로 소음에 따른 반응의 차이가 통계적으로 유의한 것으로 나타나고 있다. 일반주택의 경우 아파트에 비해 소음의 발생빈도 및 신경쓰임의 정도가 크게 나타나고 있다. 아파 트와 비교할 때 일반주택은 소음에 대해 취약한 주거형태임을 알 수 있다. 이에 비해 거주기간, 입주방식, 준공연도에 따른 발생빈도 및 신경쓰임 정도는 통계적인 유의한 차이를 나타내지 않는다. 거주기간별 소음에 대한 신경쓰임의 정도는 ' 1 년 이하, 거주의 경우 신경쓰임이 높게 나타나고 있 음을 알 수 있다. 준공 연도별 신경쓰임의 평균값 을 비교할 때, 도로교통소음, 확성기소음 및 외부 영업장소음에 대한 값이 점차 감소하는 경향으로 나타나고 있으며, 아이들 떠드는 소리, 새나 동물 들 짖는 소리에 대한 값은 증가하는 것으로 나타 나고 있다.

\section{3 내부소음환경에 대한 조사 결과}

내부소음에 대한 거주자 반응 설문 조사를 위해 선행 연구의 조사항목을 바탕으로 하여 총 16 개의 평가항목을 구성하였다.

충격소음으로는 '이웃집 현관문 여닫는 소리', ‘계단 복도의 발자국 소리', ‘엘리베이터 운행소리', '윗집 아이들 뛰는 소리', '실내에서 걷는 소리', ‘물건 떨어뜨리는 소리', 급배수소음으로는 '욕실물 급배수 소리', '변기물 급배수 소리', ‘부억물 급배 수 소리', ‘에어컨 실외기 소리'의 항목으로 평가하 였고, 공기 전달음은 ‘이야기 하는 소리'를 비롯하 여 ‘이웃집 초인종 소리', ‘부엌 음식 만드는 소리', 'TV, 라디오 소리', ‘피아노 등의 악기소리', '세탁 기 가동 소리, 등의 항목으로 평가하였다.

Table 7은 조사시기에 따른 내부소음에 대한 신 경쓰임의 정도를 순위별로 비교한 것이다. 가장 신 경쓰이는 소음은 여전히 '아이들 뛰노는 소리'로 나타났다. 두 번째로 신경쓰이는 소리는 이전 연구 에서는 급배수 관련 소음이었지만, 이 연구에서는 ‘현관문 여닫는 소리’로 나타났음을 알 수 있다. 드러난 결과로 볼 때, 벽체나 바닥 슬래브를 통해 전달되는 충격소음과 급배수 소음의 발생 빈도와 신경쓰임이 높게 나타나, 이에 대한 소음 저감 대 책이 가장 시급하게 해결해야 할 과제임을 알 수 있다.
Table 8은 내부소음에 대한 지적률 상위 5개를 추출하여 주거의 특성에 따른 조사항목의 차이를 분석한 것이다.

그 결과 외부소음에 대해 단독주택의 신경쓰임 정도가 더 크게 나타났던 반면, 내부소음에 대해 서는 공동주택의 정도가 더 높게 나타남을 알 수 있다. 각 소음에 대한 주거형태별 차이는 통계적 으로 유의하게 나타났다. 거주기간별 의식의 차이 를 비교한 결과 통계적으로 유의한 차이를 보이 지 않으나, '윗집 아이들 뛰는 소리'에 대해서는 거주기간별로 거의 유사한 정도를 나타내고 있는 반면, 그 외의 소음에 대해서는 외부소음의 경우 와 유사하게 거주기간의 짧은 경우 더 민감한 것 으로 나타난다. 입주방식별 차이 역시 뚜렷한 차 이가 없는 것으로 판단된다. 다만, 현관문 소리, 급배수 소리, 발자국 소리 등에 대해 임대, 월세 입주한 응답자의 신경쓰임 정도가 대체적으로 큰 경향이 있다.

준공연도별 차이는 몇 개의 소음 종류에 대해 유의한 차이를 보이고 있다. '현관문 여닫는 소 리'에 대해 준공연도가 현재와 멀어질수록 신경쓰 임의 정도가 크게 나타나고 있다. 이는 건물의 사 용연한이 길어짐에 따라 현관문의 노후화된 정도 를 반영한 결과로 사료된다. '계단, 복도의 발자국 소리'에 대한 응답도 유의하게 나타났는데 이 또 한 오래된 아파트의 경우 신경쓰임의 정도가 더 크게 나타남을 알 수 있다. 그러나 다른 측면에서 본다면, '윗집 아이들 뛰는 소리'에 대한 응답은 최근 아파트일수록 증가하고 있는 것으로 나타나, 건물의 노후화된 정도보다는 오히려 소음에 대한 민감도가 증가한 것이 하나의 중요한 요인으로 판단된다. 따라서 오랜 기간 동안 바닥충격음에 대한 법 기준과 연구가 진행되었음에도 불구하고 이에 대한 주민들의 피해 의식이 증가하고 있는 것을 볼 때, 효과적인 대책이 절실하게 필요하다 하겠다.

\section{4. 결 론}

설문 조사를 통해 주거환경소음에 대한 거주자의 주관 반응을 조사하여 선행연구와의 비교를 통해 변화 추이를 살펴보고자 하였다. 그 결과를 요약하 
면 다음과 같다.

(1) 주거환경 소음 중 발생빈도와 신경쓰이는 정 도가 높은 소음으로 외부소음은 '도로교통소음', 내 부소음은 '윗집 아이들 뛰는 소리'로 나타났다.

(2) 단독주택과 공동주택의 소음에 대한 의식 차 이를 비교한 결과 외부소음에 대해서는 단독주택의 빈도, 신경쓰임 정도가 높게 나타났으며, 내부소음 에 대해서는 공동주택의 빈도, 신경쓰임 정도가 높 게 나타났다.

(3) 외부소음에 대한 거주자의 만족도 조사에서 는 $57.1 \%$ 로 나타나 1996년 연구에 비해 $12.4 \%$ 더 낮게 조사되었다. 이는 거주자들의 요구에 비해 주거 환경의 개선 정도가 못 미치는 것으로 판단되 며, 지속적 연구와 법적인 개선 등을 통해 주거환경 소음을 향상시키기 위한 노력이 필요할 것으로 사 료된다.

(4) 주택 내에서 생활이 많이 이루어지는 저녁시 간대(19:00 22:00)에 가장 시끄럽다고 응답한 사람 의 비율이 $37.7 \%$ 로 가장 높게 나타났으며, 수면, 휴식, 독서 등의 정적인 활동시에 더 많은 영향을 받는 것으로 조사됐다. 이와 같은 사실은 소음에 대 한 반응 조사 및 실험에 있어서 활동 조건에 따라 결과가 달라질 수 있음을 반영한 것이며, 실험 환경 의 조건 설정에 중요한 근거로 사용될 수 있을 것 이다.

(5) 내부소음에 대한 신경쓰임의 정도를 분석한 결과, 아파트의 준공연도가 오래된 것일수록 높게 나타났다. 그러나 '윗집 아이들 뛰는 소리'에 대해 서는 최근 준공된 아파트의 값이 높게 나타났다. 더 욱이 기존 연구에서 가장 신경쓰이는 소음이었던 바닥충격음이 아직도 가장 신경쓰이는 것으로 나타 남에 따라 이에 대한 합리적인 대책이 필요한 것으 로 사료된다.

\section{후 기}

이 논문은 2011년 정부(교육과학기술부)의 재원 으로 한국연구재단의 지원(2009-0072945) 및 2011 년 교육과학기술부로부터 지원받아 수행된 연구임 (지역거점연구단육성사업/바이오하우징연구사업단).

\section{참 고 문 헌}

(1) National Environmental Dispute Resolution Commission, 2010, Statics of Dispute Resolution.

(2) Kim, S. W., et al., 1986, A Study on the Indoor Noise Limits of Apartment Houses, Korea National Housing Corporation.

(3) Park, J. U., 2006, Variations of Subjective Responses to Environmental Noises in Apartment House, Master's Degree - Thesis, Graduate School of Industry Technology in Chonnam National University.

(4) Kwark, K. S. and Park, P. J., 1996, A Research of Residents' Subject Opinion on the Apartment Noise, Journal of the Korean Housing Association, Vol. 1, No. 2, pp. 95 101.

(5) Park, J. U., Jung, K. Y. and Kim, S. W., 1996, Variations of Subjective Responses to Environmental Noises in Apartment House, Proceedings of the KSNVE Annual Spring Conference, pp. 34 40.

(6) Song, G. G., et al., 2008, A Study on the Subjective Responses to Environmental Noises, Proceedings of the KSNVE Annual Spring Conference, pp. 5 8. 